\title{
La relevancia conceptual de Gadamer
}

\author{
Raúl Alcalá
}

$\mathrm{E}$

n nuestros días, la crisis conceptual por la que la filosofía está atravesando ha tenido diferentes consideraciones, desde aquellos que pretenden el abandono total de lo que podríamos llamar la base conceptual del pensamiento moderno, hasta los que buscan una revisión completa de dicha base. Entre estos últimos tiene un lugar importante la figura de Gadamer, quien lleva a cabo una revisión y propuesta de cambio conceptual que ha permitido no perderse en ese mar de confusiones que es la posmodernidad.

Por lo anterior, no debe extrañarnos que estemos de acuerdo con Ambrosio Velasco cuando sostiene que la reelaboración que Gadamer realiza sobre los conceptos de la modernidad permite evitar las aporías y dilemas a que nos arrastra el extremismo posmoderno. Ciertamente, el reducido espacio que ocupa el artículo de Velasco no le permite desarrollar ampliamente el pensamiento gadameriano sobre los conceptos considerados ni tomar en cuenta todos, sino sólo los más importantes. ${ }^{1}$

Sin embargo, creo que los estudiosos de Gadamer se olvidan de la reelaboración de uno de los conceptos más importantes de su pensamiento, que le permite incluso criticar fuertemente la noción de método. Me refiero al concepto de experiencia. Si tomamos en cuenta nuestra herencia moderna encontramos, entre otras cosas, las nociones de racionalidad y experiencia como la base sobre la que se asienta el método que permite la obtención de conocimiento. Ambrosio Velasco, como muchos de los estudiosos de Gadamer, recupera la noción de racionalidad pero se olvida de la de experiencia y, en ese sentido, la crítica gadameriana a la modernidad se debilita.

${ }^{1}$ Ambrosio Velasco, "La relevancia del pensamiento de Gadamer en la filosofía: más allá de la modernidad y la posmodernidad”, en Revista del Colegio de Filosofía. Theoría, núm 7. México, unAm, Facultad de Filosofía y Letras, diciembre, 1998, pp. 55-66. 
Curiosamente, Velasco remite en la cita doce a la parte de la obra en la que Gadamer habla de la formación, pero lo hace como de pasada, es decir, sin darle la importancia que se merece dicha noción. Sin embargo, ésta es una noción que está muy cercana a la de experiencia. Aquí sólo hablaremos de esta última.

Gadamer nos revela la deficiencia que la noción de experiencia ha adquirido al haber sido orientada hacia la ciencia, olvidándose así de su carácter histórico. Se le concibe, en otros términos, como sujeta a control y como repetitiva, y, en tanto tal, como un recurso idóneo para la obtención de conocimientos para el método de la ciencia. En este sentido se ha ocultado su verdadero proceso, pues la experiencia no puede ser reducida a la formación de generalidades típicas, ya que tiene más que nada un carácter negativo. Expliquemos esto.

Para Gadamer la experiencia es única, no puede hacerse dos veces la misma experiencia, porque cuando se le ha hecho ya se le posee. Sólo será nueva cuando surja un hecho inesperado, de tal modo que el que experimenta se hace consciente de su experiencia y reconoce que las anteriores eran incorrectas, de aquí su carácter negativo. Esto lo lleva a sostener que una persona experimentada no puede ser reducida al cúmulo de experiencias pasadas, sino que es aquella que está abierta a nuevas experiencias, que está capacitada para nuevas experiencias y aprender de ellas, y en este sentido es la más radicalmente no dogmática, por ello rebasa todo conocimiento conceptual.

Gadamer considera que hay por lo menos dos ejemplos de este tipo de experiencia, la de la historia y la del arte, que no se dejan atrapar por un recurso meramente lingüístico. La última le permite hablar de la verdad en el arte y la primera muestra que la historia tiene vigencia en el presente, que los acontecimientos del pasado tienen efectos en el presente, es decir, se concibe la historia como efectual. Tener conciencia de esto es lo que da paso a la presencia de un caso especial de experiencia: la experiencia hermenéutica, a la que tanta atención le presta Gadamer. Aquí no pretendo hacer un estudio sobre la noción que estamos considerando sino sólo hacer una llamada de atención al respecto, por ello creo conveniente, para finalizar mi comentario sobre este punto y pasar a otro, traer a colación la siguiente cita:

Cuando hacemos una experiencia con un objeto esto quiere decir que hasta ahora no habíamos visto correctamente las cosas y que es ahora cuando por fin nos damos cuenta de cómo son. La negatividad de la experiencia posee en consecuencia un particular sentido productivo. No es simplemente un engaño que se vuelve visible y en consecuencia una corrección, sino lo que se adquiere es un saber abarcante. En consecuencia el objeto con el que se hace una experiencia no puede ser 
uno cualquiera sino que tiene que ser tal que con él pueda accederse a un mejor saber, no sólo sobre sí mismo sino también sobre aquello que antes se creía saber, esto es, sobre su generalidad. ${ }^{2}$

Como se puede notar esto establece una divergencia clara con los filósofos de la ciencia que menciona Velasco, aunque es cierto que respecto a los otros conceptos hay una cercanía muy fuerte.

Por otra parte, a mí no me queda claro si Velasco considera la posibilidad de que haya fusión de horizontes entre culturas que tienen diferente historia, pero uno se queda con la impresión de que aceptaría tal fusión, sobre todo, cuando se relacionan el final del inciso objetividad y comprensión, con el final del inciso sobre racionalidad. Sin embargo, me parece que es posible entablar un diálogo con otras culturas sin que haya fusión de horizontes, pues éstos más bien parecen necesitar la pertenencia a la misma historia. A este respecto es sintomático que el propio Gadamer, cuando habla de diálogo entre comunidades distintas - ver la cita veinte de Velasco-, no se remite a la fusión de horizontes, ni siquiera la menciona.

Para finalizar, me parece que la objetividad en Gadamer está mejor desarrollada precisamente en la parte en la que trata con la noción de experiencia que en el trabajo del que Velasco toma la cita ocho, pues en éste lo que Gadamer pretende es mostrar cuáles son las tres bases que sirven de fundamento a la filosofía actual, que para él son: los griegos, Kant y Hegel, y no tanto para analizar la noción de objetividad. ${ }^{3}$

${ }^{2}$ Hans-Georg Gadamer, Verdad y método I. 6a. ed. Salamanca, Sígueme, 1996, pp. 428-429.

${ }^{3}$ La cita que hace Velasco está tomada de la versión en lengua inglesa; la versión en español aparece en Gianni Vattimo, La secularización de la filosofía. Madrid, Gedisa, 1992. 